\title{
Nonlinear Lining Design Considering Soil-Lining Interaction, Case Study: Gilavand Tunnel
}

\author{
H. Lavasani H., Sharif Tehrani S.; \\ Department of civil Engineering, Engineering Faculty, \\ Kharazmi University, Tehran, Iran \\ Received: 26 Aug 2013 \\ Revised: 30 Dec 2014
}

\begin{abstract}
There are various methods for the analysis of the interactional behavior of the surrounding land, using the lining structure which is the most common method of deigning lining structure tools for the static loads by using the hyper static methods. In recent years, there has been a question that depicts whether this method provides the best results in designing the tunnel structure or not. Due to the nonlinear behavior of the earth surrounding the lining structure, utilizing the lining method could lead to conservative results in the design. If it is possible to somehow find the forces caused by the real behavior of the land surrounding the lining structure influencing the structure and conduct the design based on them, more optimal results would be obtained. This study is based on the actual behavior of the land surrounding the lining structure and the displacement of the structure caused by forces with linear behavior in the static design according to the non-linear behavior of the land around the tunnel structure. The
\end{abstract}

*Corresponding author lavasani@khu.ac.ir 
behavior is modeled using the non-linear programs and the forces

affecting the lining of the structure will be inference. Also there is a case study based on this method in which the soil interaction with the tunnel analysis and designing the lining structure was first performed and eventually the obtained results were compared with the hyper static method. In this paper, analysis of maintenance system with lower thicknesses considering land-shield, indicated that applying the reinforced concrete with $40 \mathrm{~cm}$ thickness has the potential to tolerate the applied load but lining with $45 \mathrm{~cm}$ thickness is capable of tolerating the loads of design and it can be concluded that applying the simulation method combined with the soil and structure besides considering the nonlinear behavior of the soil leads to more economical results in a project.

Keyword: nonlinear design, soil-lining interaction, Gilavand Tunnel, underground Structure.

\section{Introduction}

Construction of tunnels and underground spaces with any purpose includes both the processes of excavation and shielding [1-8]. The coverage of the areas is done in order to maintain the safety of people and equipment during construction and the realization of the functional demands during operation [9-16]. The knowledge of keeping the earth balanced is the science that implies the rock mass behavior in the transition from the initial equilibrium state to another equilibrium state. The science provides the necessary ground for the design of the 
bearing systems and lining the underground spaces in order to prevent the ceiling, floor and walls loss or fragmentation and providing the safety in an economical manner. The easiest way to maintain the tunnel structure's balance includes placing a rigid casing and body after tunneling in a way that any possibility of lateral rocks' change of position is cancelled [7]. One the other hand, it is possible to use flexible bearing tools that do not resist against the lateral rocks and provide the possibility of displacement of the rocks. So the solution of lining problem includes determining the best method based on safety and economy which is combined with other tunneling activities such as ventilation and transportation [8]. The rock and soil mechanics principles are applied in designing the best and most suitable lining. Each of the lining systems are analyzed based on the stress distribution or force and relative or absolute deformation of the structure. In this way, the system stability situation is determined through choosing a proper submission criterion. One of the major difference of the analysis of the underground structures with the analysis of the structures made of synthetic materials used in other fields of engineering is that the design engineer unlike the structuralbuilding does not have wide options of the environmental materials (lateral rocks) or the position of the structure. Then the next analysis of each systems is considering factors such as the stability of the structure, costs and the degree of fitness with the other tunneling activities, it is possible to choose the best system. Another method 
was utilized for a tunnel in Cairo in the earth with the combination of sand and clay in 1998 by Joachim et al. It is assumed that the soil and the structure have full continuum at the junction and the deformations are small but this assumption is not true in cases that the soil is made of weaker materials such as sand or mud. In the nonlinear analysis the tunnels surrounded by sand and clay soil with concrete cover, the nonlinearity include three important parameters:

1. The nonlinear behavior of concrete structures and soil.

2. The impact of great deformations.

3. The nonlinear contact between the concrete structure and the surrounding soil (slip between the materials).

Youakim et al provided a model of non-linear combination of concrete and soil assuming huge deformations and studied the change of above parameters in the predicted settlement or changes in stress distribution in the tunnel entrance [17]. They used the increased stress-strain formula known as elastic hypochlorite model for the lining concrete structure failure because the concrete is an irreversible material and dependent on load. This model is actually the extension of the hypo elastic basic model with the capacity to calculate biaxial and triaxial stress in which the tensile cracks and compressive failure conditions are considered. Furthermore, the $t$ otal Lagrangian formula for the analysis of great deformations assuming the nonlinearity of the structure material and geometry as well as great displacements and rotations and small strains were considered in this study [17]. 
Cao Yuan et al (2011) conducted a study on a water tunnel in China to calculate water hammer to the tunnel structure. Since the tunnel was long, the analysis with common methods was complicated. Also the simulation of the effects of water hammer to the tunnel structure using common methods had many problems due to severe water flown into the tunnel. That is why Cao Yuan et al, used nonlinear multi-scale modeling methods to analyze the tunnel. Not only had this method met their needs to simulate the phenomenon of water hammer along the tunnel, but also it was used for structural details of a part of the tunnel [15]. The main purpose of this study is analyzing the interaction between the host land and the lining structure using distinct element numerical method and design the lining structure based on the obtained results. Finally, the results were compared with the conventional hyper static methods. This study is based on the actual behavior of the land surrounding, the lining structure and the nonlinear behavior and displacement structures which caused by the forces. It should be mentioned that this is different from the linear behavior model in static design mode. In addition, one case study was performed on the Gilavand tunnel and the results were compared to the common linear methods and finally both methods with their diversities were described. 


\section{Numerical Modeling Procedure and Design based on Non-Linear Behavior of Soil}

Analyzing the interaction of soil and lining was performed using FLAC4.0 program. The networking of the discrete components was considered on a rigid layer and the vertical and horizontal on the left and right boundaries are fixed and prevent modeling the movement of the soil layers. The properties of the soil and lining materials are shown in Table 1 and 2. For the purpose of simplicity, constant values of Young's modulus and shear strength drainage parameters are used for the soil layer. In the design carried out in the report of the consulting firm, lining design is utilized through the conventional method with respect to the springs with shear vertical stiffness to apply the impact of the soil on the structure. The coefficient of 1.05 is considered for the structure density. Soil motion is controlled by the tension release parameter $\alpha_{\mathrm{dec}}$ and the length of the unshielded $L$ dec zone. Also these two parameters consider the distance between the shield, soil and injecting grout. In the first step of drilling, the internal pressures $\left(\mathrm{P}_{0}\right)$ in the drilling section equals the external pressures while the shield is not installed yet. In the second apart, internal pressures are released by the $\alpha_{\mathrm{dec}}$ and in the next step the lining elements are added to the model and in the final step the value of $\alpha_{\mathrm{dec}}$ becomes zero. According to Wittke [18], environmental modeling, applying tunneling and determining the temporary storage system based on the conventional theories and finally determining the rock 
load leads for reduced arching resistance of the soil to the point that it is loosened and results in an equivalent force to rock load. According to the proposed method, the efforts made in the structure are mainly created due to its stiffness. The stiffness of the structure mainly depends on the stiffness of the structure, so it is possible to ignore the reinforcing impact in the final analysis of the strength. However in the final stage of controlling the reaction of the structure, the effect of reinforcements must be considered. It should be noted that the proposed method, only covers the ultimate maintenance system analysis with respect to the static loads. In order to determine the efforts by the earthquake in the maintenance structure, it is possible to use conventional methods such as Hshash method. It should be mentioned that methods such as spectral analysis and time analysis are also used in maintenance system design against earthquake but because of the complexity of the methods and the requirement for high computational power of the program, they are not suggested to be used in the tunnel. According to the above statements and considering the proposed method, the following steps are taken for the design of the Gilavand tunnel maintenance system. In this study, the numerical modeling of the soil environment was performed in FLAC software. Then the mechanical specifications of the soil within the arc surrounding the tunnel were reduced into $70 \%$ of the initial specification. This value is considered for the inclusion of the reduced mechanical specifications of the soil due to loosening based on 
Wittke. Also the soil resistive specifications were created a plastic zone, then by applying the equivalent structure with final lining in the model of calculations continued to achieve perfect balance. At last, after the final calculations, the axial forces and moments generated in the maintenance system were determined. Accordingly, FLAC software was suitable for modeling (Figure 1).

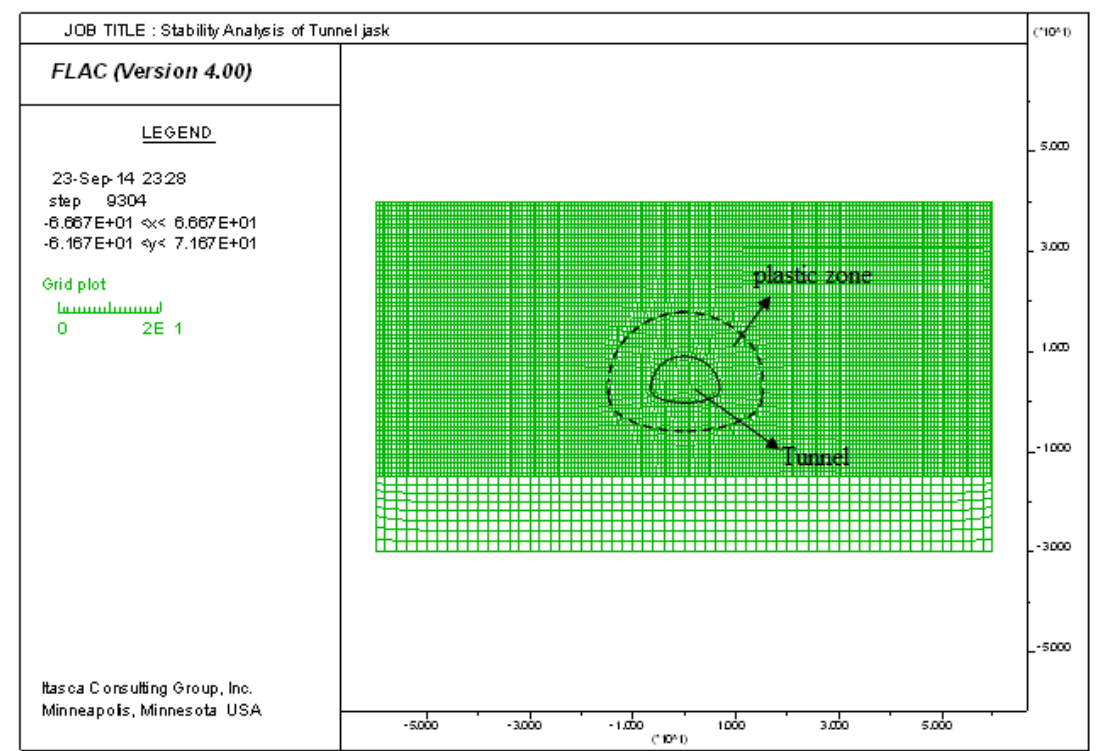

Figure 1. The general schematics of the prepared model and the plastic zone (9m) Plastic zone

Table1.The proposed geo-mechanical parameters of the materials hosting the 1direction tunnel for design based on the Phase 2 Geological report of the tunnel [20]

\begin{tabular}{|c|c|c|c|c|c|c|}
\hline $\begin{array}{c}\text { Engineering } \\
\text { Classification }\end{array}$ & $\begin{array}{c}\text { Mass } \\
\text { Resistance } \\
\text { (Mpa) }\end{array}$ & $\begin{array}{c}\text { Angle of } \\
\text { internal } \\
\text { friction } \\
\text { (Degree })\end{array}$ & $\begin{array}{c}\text { Coherence } \\
\mathrm{C}\end{array}$ & $\begin{array}{c}\text { Horizontal } \\
\text { coefficient } \\
\text { of soil stress } \\
\mathrm{K}_{0}\end{array}$ & $\begin{array}{c}\text { Elasticity } \\
\text { modulus } \\
\text { Edm } \\
(\mathrm{Mpa})\end{array}$ & $\begin{array}{c}\text { Density } \\
\mathrm{gr}^{2} \mathrm{~cm}^{2}\end{array}$ \\
\hline Unit Qf & 1 & 30 & 40 & 0.5 & 300 & 1.8 \\
\hline
\end{tabular}


Table 2. Specifications considered of lining materials

\begin{tabular}{|c|c|c|c|}
\hline Type of material & $\begin{array}{c}\text { Modulus (Kg / } \\
\mathrm{cm} 2)\end{array}$ & Poisson coefficient & Resistance \\
\hline & & & \\
\hline Concrete & 240000 & 0.2 & $\mathrm{~F}_{\mathrm{c}}=210 \mathrm{Kg} / \mathrm{cm} 2$ \\
\hline Steel (Armature) & 2000000 & 0.3 & $\mathrm{~F}_{\mathrm{y}}=4200 \mathrm{Kg} / \mathrm{cm} 2$ \\
\hline
\end{tabular}

\section{Case Study}

Gilavand bypass route is considered as Tehran-North belt path in the southern part of Gilavand city. The path includes two reciprocating axis, due to the morphology of the mountain area, each axis would have two tunnels. One of them is stony like the Green tuffs of Karaj and the other one is alluvial. In this article, the tunnel in the delta region is analyzed due to greater sensitivity. The general characteristics of these tunnels within the delta region are as follows [22]:

- The right side tunnel: The tunnel length is about 477 meters with a $1 \%$ slope outward into the tunnel inlet. The average elevation is $1884 \mathrm{~m}$ above the sea level and it will be drilled along 110- N Degree.

- The left side tunnel: The tunnel is about 465 meters long and $0.8 \%$ longitudinal slope outward into the tunnel inlet. The average elevation is $1885 \mathrm{~m}$ above the sea level and it will be drilled along 110- N Degree and then 130 - N Degree. The distance between the right and left side tunnels is $60 \mathrm{~m}$.

The area of the construction of the Gilavand southern bypass tunnels is along the southern Alborz sedimentary-structural zone. In this area after periods of erosion and deposition of Paleocene (Fajan 
conglomerate) the land was covered by a shallow sea which was perfect place for deposition of a former Eocene limestone nummulites (Ziarat Structure) and then green Eocene igneous rock [20]. The gradual subsidence of this shallow basin has led to the formation of a bulk about 3300 meter of tuff and nowadays layers are known as Karaj formation (Eocene). After the shaping of Karaj Formation during Quaternary glacial period and the formation of large floods, a large volume of alluvial zones formed in the foothills and buried the outcrops. An instance of these alluvial lands has covered the surface of the outcrops as an alluvial fan within the area of tunnel 1. The main units surrounding the tunnel include young alluvial deposits and at some points the rock tuff Ekt. According to studies conducted, a large part of the tunnel is hosted by alluvial units. The geo-mechanical characteristics of the host units are a function of alluvial material and their engineering classification is based on visual geology characteristics and laboratory studies. According to the geological studies, the rock mechanics and laboratory results the features of the materials hosting the tunnel are estimated and presented in Table 1-4 [20].

\section{The results of designing temporary maintenance}

Considering the relatively large distance between the right and left tunnels and the lack of affecting the drilling of each tunnel on the other one, the stability analysis of one tunnel under overburden critical condition was performed. Designing the method of drilling and 
temporary maintenance of these tunnels is performed by the combination of convergence-confinement and two dimensional numerical simulations. In order to use these methods, the ring cut is considered as the drilling method and a combination of shotcrete and steel frame methods are considered as the temporary maintenance systems. The highest overburden on right and left side of the tunnels are related to $3+080 \mathrm{~km}$ and equals $40 \mathrm{~m}$. According to the conducted analysis, results for the critical stability section of the tunnel is in $r+80$ and the highest plastic zone range is around the tunnel. The final results obtained from temporary maintenance system of these tunnels are presented in Table 3.

Table3. The summery of temporary maintenance system results in the tunnel [22]

\begin{tabular}{|l|l|l|l|}
\hline Section & Drilling method & temporary maintenance system & $\begin{array}{l}\text { The dead load on the final } \\
\text { maintenance system }\end{array}$ \\
\hline $3+080$ & Ring-cut & $\begin{array}{l}20 \mathrm{Cm} \text { Shotcrete + IPE18 } \\
\text { steel frames with } 1 \text { meter } \\
\text { distance }\end{array}$ & $\begin{array}{l}\text { Equivalent to 12.5 tons per } \\
\text { meter }\end{array}$ \\
\hline
\end{tabular}

\section{The results of lining design based on conventional Hyper Static method}

According to the available reports of Gilavand project, designing the final lining is done by a procedure called Hyper Static method. Accordingly, the design is performed for two various combinations of loading ODE (Operating design earthquake) and it should be controlled for MCE (Maximum credible earthquake). The loading compositions used include [9]:

$$
\mathrm{ODE}=1.3 \mathrm{OVR}+1.3 \mathrm{EQ}+1.05 \mathrm{EX}
$$




$$
\mathrm{MCE}=1.0 \mathrm{OVR}+1.0 \mathrm{EQ}+1.0 \mathrm{EX}
$$

Where:

OVR : the dead load created by the plastic zone made by drilling EQ: The load caused by the earthquake EX: The load caused by the lining weight

Based on this method's analysis and the Sap program, the final maintenance systems is $50 \mathrm{~cm}$ of floor lining with 2 rows of $\varphi 25$ armature with $20 \mathrm{~cm}$ distance. Also in the lateral arcs, the lining is reinforced by two additional rows of $\varphi 25$ armatures. In the analysis, the behavior of the structure is first separately analyzed under dead loads resulting from drilling and the lining weight, then analyzed under the earthquake load in the Sap software. In order to apply the earthquake load, the model of Hashash et al [21] is used. According to this model, using the mechanical characteristics of the land, structure and the features of the earthquake, the maximum displacement created in the structure is calculated and applied as a force of displacement from one point to another from the lining.

In the next parts, the maintenance system was designed by choosing various final maintenance systems (different lining thicknesses). The first design is performed for the intended thickness in the consultant's report and then through step by step adding to the thickness, the thinner maintenance system with lower reinforcement is used. In addition, considering the design performance of the ODE loading and MDE controlling, only the ODE loading is utilized in this research for each section. 
Table4. The input parameters for $50 \mathrm{Cm}$ thick lining

\begin{tabular}{|c|c|c|c|}
\hline \multicolumn{4}{|c|}{ Input parameters - ODE } \\
\hline \multicolumn{4}{|c|}{ Geotechnical Parameters, } \\
\hline Unit Weight of the medium , & $\boldsymbol{\rho m}=$ & 1800 & $\mathrm{Kg} / \mathbf{m}^{\wedge} \mathbf{3}$ \\
\hline Poisson's ratio of the medium, & $\mathbf{v m}=$ & 0.25 & - \\
\hline Modulus of elasticity of medium, & $\mathbf{E m}=$ & $3.00 \mathrm{E}+05$ & Kpa \\
\hline Shear Modulus of medium, & $\mathrm{Gm}=$ & 120000 & Kpa \\
\hline \multicolumn{4}{|c|}{ Tunnel Parameters, } \\
\hline Lining thickness, & $\mathbf{t}=$ & 0.5 & $\mathbf{m}$ \\
\hline Lining diameter, & $\mathbf{d}=$ & 10 & $\mathbf{m}$ \\
\hline Lining radius, & $\mathrm{r}=$ & 5 & $\mathrm{~m}$ \\
\hline Depth below ground surface, & $\mathbf{h}=$ & 44 & $\mathbf{m}$ \\
\hline Area of Tunnel Lining (per unit width), & $\mathbf{A l}=$ & 0.5 & $\mathrm{~m}^{\wedge} \mathbf{2} / \mathbf{m}$ \\
\hline Moment of inertia of the tunnel lining, & $\mathrm{Ic}=$ & 0.0104167 & $\mathrm{~m}^{\wedge} 4 / \mathrm{m}$ \\
\hline Poisson's ratio of the Concreate, & $\mathbf{v I}=$ & 0.2 & - \\
\hline Concrete yield strength, & $\mathbf{f c}=$ & $2.40 \mathrm{E}+04$ & Kpa \\
\hline Concrete Young's Modulus, & $\mathrm{E} 1=$ & $2.32 \mathrm{E}+07$ & Kpa \\
\hline \multicolumn{4}{|c|}{ Earthquake Parameters, } \\
\hline Magnitude , & $\mathbf{M w}=$ & 6.5 & - \\
\hline Source to site distance, & $\mathbf{d s}=$ & $0-20$ & $\mathbf{K m}$ \\
\hline Peak ground particle acceleration at surface, & $\operatorname{amax}=$ & 0.15 & $\mathbf{g}$ \\
\hline Apparent velocity of S_wave propagation in medium, & $\mathrm{Cm}=$ & 258.2 & $\mathrm{~m} / \mathrm{s}$ \\
\hline \multicolumn{2}{|l|}{ Ratio of peak ground velocity $(\mathrm{cm} / \mathrm{s})$ to peak ground acoeleration(g), } & 94 & - \\
\hline \multicolumn{2}{|l|}{ Ratio of peak ground displacement $(\mathrm{cm})$ to peak gronnd acceleration(g), } & 35 & - \\
\hline \multicolumn{2}{|l|}{ Ratios of ground motion at depth to motion at ground surface, } & 0.7 & - \\
\hline \multirow{3}{*}{ Ground motion at depth of tunnel, } & as $=$ & 0.105 & $\mathrm{~g}$ \\
\hline & $\mathrm{Vs}=$ & 0.0987 & $\mathrm{~m} / \mathrm{s}$ \\
\hline & $\gamma \max =$ & 0.0003823 & - \\
\hline
\end{tabular}

\section{$50 \mathrm{~cm}$ thick lining}

According to ODE loading, the rock load coefficient should be 1.3. Due to the density of the soil, the maximum height of the arc for such force equals:

$$
h=\frac{\text { Rock Load }}{\text { Soil density }} \times 1.3=\frac{12.5}{1.8} \times 1.3 \simeq 9 \mathrm{~m}
$$

Due to the earthquake load application, application of the quasi static method (applying the displacement force) is done by first considering the displacement caused by the earthquake as it is 
obtained by the method of Hashash et al. In order to summarize the calculations, these relations are presented through formulation in excel.

Table5. The results of $50 \mathrm{~cm}$ thick lining

\begin{tabular}{|c|c|c|c|c|c|}
\hline \multicolumn{6}{|c|}{ Calculation Results } \\
\hline \multirow{8}{*}{ 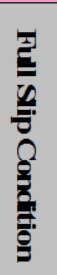 } & \multirow{4}{*}{$\begin{array}{l}\bar{Q} \\
\mathbb{8} \\
\mathbb{9}\end{array}$} & \multirow{3}{*}{$\begin{array}{l}\text { 1- Determine the racking ratio }(R n) \text { and the } \\
\text { displacement term } \Delta \text { d_free_field, }\end{array}$} & $\alpha_{n}=$ & 0.088252 & - \\
\hline & & & $\mathrm{Rn}=$ & 2.76 & - \\
\hline & & & $\Delta d$ free_field $=$ & 0.0019 & $\mathrm{~m}$ \\
\hline & & 2-Determined displacement, & $\Delta d n \_$lining $1=$ & 0.00527 & $\mathrm{~m}$ \\
\hline & \multirow{4}{*}{ 嘅 } & \multirow{3}{*}{$\begin{array}{l}\text { 1-flexibility ratio }(F) \text {, full-slip lining } \\
\text { response coefficient }(K 1) \text { \& Racking ratio, }\end{array}$} & $\mathrm{F}=$ & 19.8297 & - \\
\hline & & & $\mathrm{K} 1=$ & 0.20853 & - \\
\hline & & & $\mathrm{R}=$ & 2.76 & - \\
\hline & & 2- Determined displacement, & $\Delta d$ lining $2=$ & 0.00527 & $\mathrm{~m}$ \\
\hline
\end{tabular}

\begin{tabular}{|c|c|c|c|c|c|}
\hline \multirow{7}{*}{ 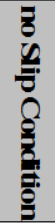 } & \multirow{3}{*}{ 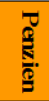 } & \multirow{2}{*}{ 1- Determine the racking ratio $(R)$, } & $\alpha=$ & 0.100859 & - \\
\hline & & & $\mathrm{R}=$ & 2.73 & - \\
\hline & & 2- Determined displacement, & $\Delta \mathrm{dn} \_$lining $3=$ & 0.005209 & $\mathrm{~m}$ \\
\hline & \multirow{4}{*}{ 结 } & \multirow{3}{*}{$\begin{array}{l}\text { 1-Compressibity ratio C, no-slip lining } \\
\text { response coefficient(K.2) \& Racking ratio }\end{array}$} & $\mathrm{C}=$ & 0.1983 & $\begin{array}{lll}- & \\
- & \end{array}$ \\
\hline & & & $\mathrm{K} 2=$ & 1.17633 & - \\
\hline & & & $\mathrm{R}=$ & 2.76 & - \\
\hline & & 2-Determined displacement, & $\Delta d$ lining $4=$ & 0.00527 & $\mathrm{~m}$ \\
\hline
\end{tabular}

\section{Final $\Delta d$ lining is equal to}

0.0053 m

Based on the above calculations, the maximum displacement applied on the lining is $5.3 \mathrm{~mm}$. Since Hashash et al considered the surrounding land in the calculations for the application of this force, the land surrounding the structure are eliminated at the beginning and then by fixing the structure's floor, the obtained displacement is enforced to the top. In order to observe the loading combination, this value is multiplied by 1.3 and finally entered the program as the criterion of the displacement load $(6.9 \mathrm{~mm})$. Due to the nature of Hashash et al method and considering that the environment effect is observed in calculating the displacement created in the structure during the earthquake, the induced displacement to the structure is 
applied to the structure by omitting the surrounding forces. In these circumstances, the resulting forces and moments generated at the lining in section are represented in Figures 2 and 3.

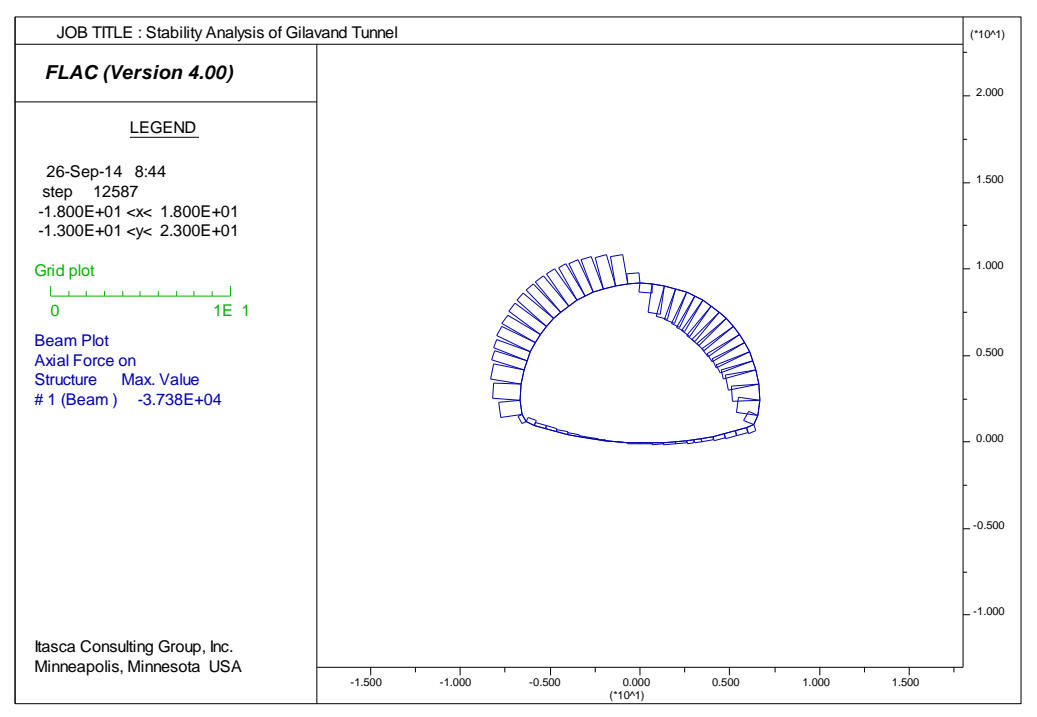

Figure2. Axial forces created in the structure after the final calculations

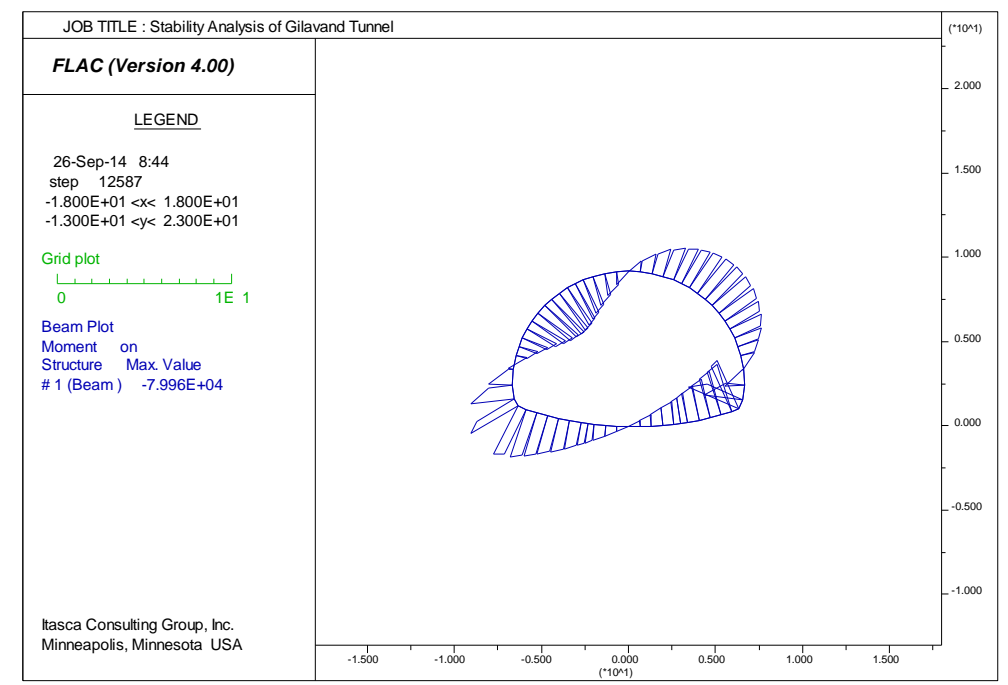

Figure3. The bending moments created in the structure after the final calculations 
The results of the above analysis include axial forces and bending moments under the static and dynamic loads separately. In order to control the response of the structure, the sum of the forces and moments must be analyzed based on the bearing capacity of the structure. Due to controlling the lining structure, multiple methods are used. Considering the use of the axial force- bending moment push method, the same method is used for analyzing the conditions of the final tunnel structure. In order to determine axial force- bending moment diagram of the reinforced concrete, the Section Builder program was used. Using the loading combination coefficients, the final characteristics of the concrete and the structure for the reinforced concrete section are considered (Table 2).

Based on the properties of the final axial force- bending moment curve is obtained for $50 \mathrm{~cm}$ section and considering the 2 reinforcement with $25 \mathrm{~mm}$ diameter and $20 \mathrm{~cm}$ distance (Fig. 4). Also the ratio of axial forces and bending moments created in the structure in two states of applying static and dynamic loads is obtained considering the non-linear behavior of the land and presented by points. The structure has the capacity to tolerate the attempts. Also within the arc (Fig.5) the structure needs to be strengthened, which is why two rows of reinforcements are added. The results of analysis in this part indicate the consistence of the results with the design of the consultant engineers. 


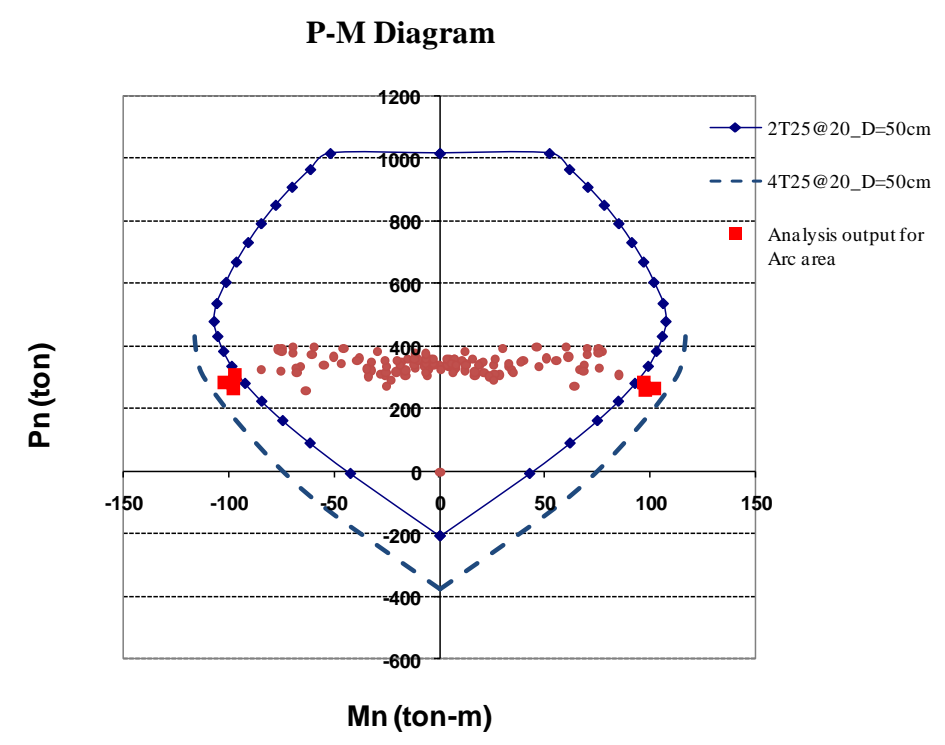

Figure4. The capacity of axial force-bearing moment of the structure versus the results of analysis

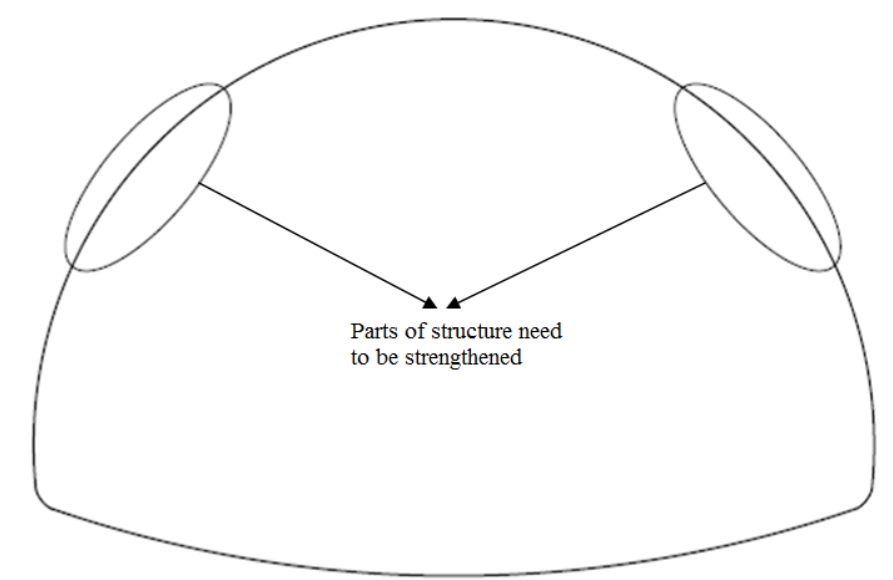

Figure 5. Lateral arc ranges of the structure that need to be strengthened

As previously mentioned, by considering lining thickness of $50 \mathrm{~cm}$ and its reinforcement with two rows of armatures with a diameter of $25 \mathrm{~mm}$ with $20 \mathrm{~cm}$ distance and adding two additional rows within the 
lateral arcs, the structure has the ability to tolerate the created forces and moments. As shown in Figure 5, the structure section has the potential to tolerate higher axial forces as well. Since the concrete structure is mainly responsible for bearing axial forces, it is possible to reduce the lining structure thickness by maintaining structural stability. To do so the analysis should be performed through considering lower lining thickness in the Flac Software and then its capability to tolerate new forces and moments was analyzed.

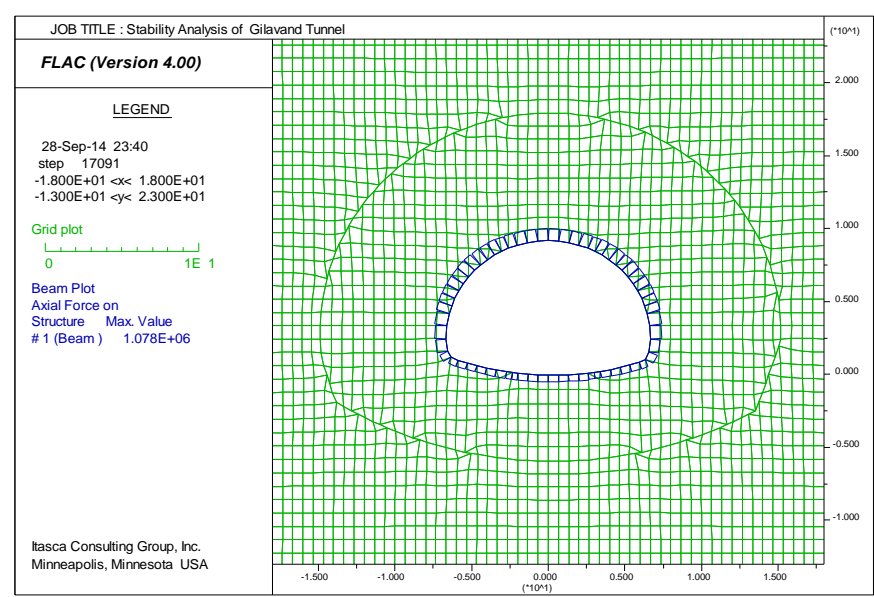

Figure6. The axial loads created in the structure after the final calculations

\section{Cm lining thickness}

In this part, using lining structures below $50 \mathrm{~cm}$ thickness is analyzed. Therefore, the carried out analysis will be repeated by considering the lining thickness of $45 \mathrm{~cm}$. After the final calculations, in the level of applying static loads of operation period the axial forces and moments in the maintenance system are considered with respect to the structural lining thickness of $45 \mathrm{~cm}$ 


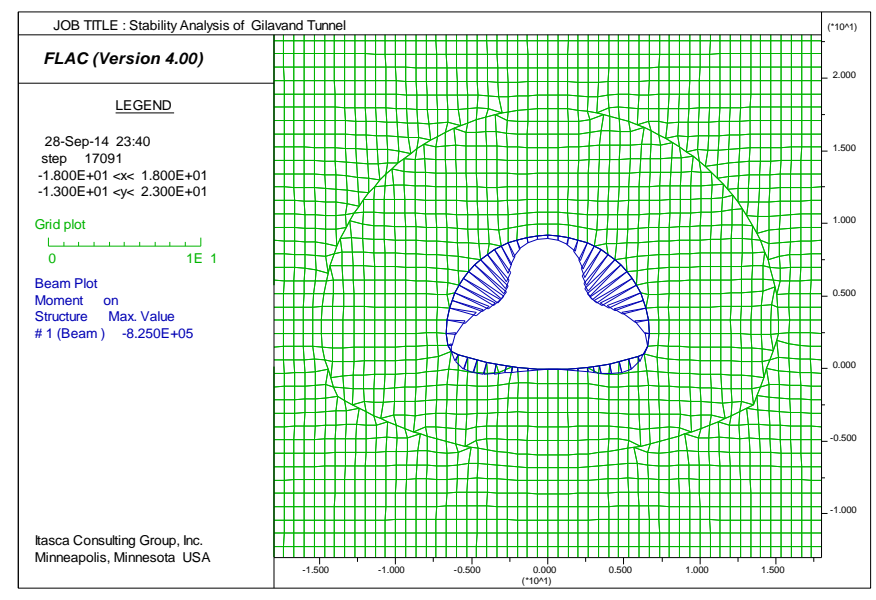

Figure7. The bending moments created in the structure after the final calculations

Table6.The input parameters for lining with the thickness of $45 \mathrm{~cm}$

\begin{tabular}{|c|c|c|c|}
\hline \multicolumn{4}{|c|}{ Input parameters - ODE } \\
\hline \multicolumn{4}{|c|}{ Geotechnical Parameters, } \\
\hline Unit Weight of the medium, & $\rho \mathrm{m}=$ & 1800 & $\mathrm{Kg} / \mathrm{m}^{\wedge} 3$ \\
\hline Poisson's ratio of the medium, & $v \mathrm{~m}=$ & 0.25 & - \\
\hline Modulus of elasticity of medium, & $\mathrm{Em}=$ & $3.00 \mathrm{E}+05$ & Kpa \\
\hline Shear Modulus of medium, & $\mathrm{Gm}=$ & 120000 & Kpa \\
\hline \multicolumn{4}{|c|}{ Tunnel Parameters, } \\
\hline Lining thickness, & $\mathrm{t}=$ & 0.45 & $\mathrm{~m}$ \\
\hline Lining diameter, & $\mathrm{d}=$ & 10 & $\mathrm{~m}$ \\
\hline Lining radius, & $\mathrm{r}=$ & 5 & $\mathrm{~m}$ \\
\hline Depth below ground surface, & $\mathrm{h}=$ & 44 & $\mathrm{~m}$ \\
\hline Area of Tunnel Lining (per unit width), & $\mathrm{Al}=$ & 0.45 & $\mathrm{~m}^{\wedge} 2 / \mathrm{m}$ \\
\hline Moment of inertia of the tunnel lining, & $\mathrm{Ic}=$ & 0.0075938 & $\mathrm{~m}^{\wedge} 4 / \mathrm{m}$ \\
\hline Poisson's ratio of the Concreate, & $v \mathrm{l}=$ & 0.2 & - \\
\hline Concrete yield strength, & $f^{\prime} c=$ & $2.40 \mathrm{E}+04$ & Kpa \\
\hline Concrete Young's Modulus, & $\mathrm{El}=$ & $2.32 \mathrm{E}+07$ & Кра \\
\hline \multicolumn{4}{|c|}{ Earthquake Parameters, } \\
\hline Magnitude, & $\mathrm{Mw}=$ & 6.5 & - \\
\hline Source to site distance, & $\mathrm{ds}=$ & $0-20$ & $\mathrm{Km}$ \\
\hline Peak ground particle acceleration at surface, & $\operatorname{amax}=$ & 0.15 & $\mathrm{~g}$ \\
\hline Apparent velocity of S_wave propagation in medium, & $\mathrm{Cm}=$ & 258.2 & $\mathrm{~m} / \mathrm{s}$ \\
\hline \multicolumn{2}{|l|}{ Ratio of peak ground velocity $(\mathrm{cm} / \mathrm{s})$ to peak ground acceleration $(\mathrm{g})$, } & 94 & - \\
\hline \multicolumn{2}{|l|}{ Ratio of peak ground displacement $(\mathrm{cm})$ to peak ground acceleration $(\mathrm{g})$, } & 35 & - \\
\hline \multicolumn{2}{|l|}{ Ratios of ground motion at depth to motion at ground surface, } & 0.7 & - \\
\hline \multirow{3}{*}{ Ground motion at depth of tunnel, } & as $=$ & 0.105 & $\mathrm{~g}$ \\
\hline & $\mathrm{Vs}=$ & 0.0987 & $\mathrm{~m} / \mathrm{s}$ \\
\hline & $\gamma \max =$ & 0.0003823 & - \\
\hline
\end{tabular}


Table 7.The calculation results of lining with the thickness of $45 \mathrm{~cm}$

\begin{tabular}{|c|c|c|c|c|c|}
\hline \multicolumn{6}{|c|}{ Calculation Results } \\
\hline \multirow{8}{*}{ 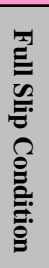 } & \multirow{4}{*}{ 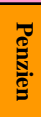 } & \multirow{3}{*}{$\begin{array}{l}\text { 1- Determine the racking ratio }(\mathrm{Rn}) \text { and the } \\
\text { displacement term } \Delta \mathrm{d} \text { _free_field, }\end{array}$} & $\alpha n=$ & 0.064335 & - \\
\hline & & & $\mathrm{Rn}=$ & 2.82 & - \\
\hline & & & $\Delta$ d_free_field $=$ & 0.0019 & $\mathrm{~m}$ \\
\hline & & 2- Determined displacement, & $\Delta \mathrm{dn} \_$lining $1=$ & 0.00539 & $\mathrm{~m}$ \\
\hline & \multirow{4}{*}{ 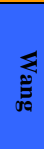 } & \multirow{3}{*}{$\begin{array}{l}\text { 1-flexibility ratio }(F) \text {, full-slip lining } \\
\text { response coefficient(K1) \& Racking ratio, }\end{array}$} & $\mathrm{F}=$ & 27.2012 & - \\
\hline & & & $\mathrm{K} 1=$ & 0.15543 & - \\
\hline & & & $\mathrm{R}=$ & 2.82 & - \\
\hline & & 2- Determined displacement, & $\Delta d$ dining $2=$ & 0.00539 & $\mathrm{~m}$ \\
\hline
\end{tabular}

\begin{tabular}{|c|c|c|c|c|c|}
\hline \multirow{7}{*}{ 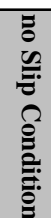 } & \multirow{3}{*}{ 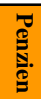 } & \multirow{2}{*}{ 1- Determine the racking ratio $(\mathrm{R})$, } & $\alpha=$ & 0.073526 & - \\
\hline & & & $\mathrm{R}=$ & 2.79 & - \\
\hline & & 2- Determined displacement, & $\Delta$ dn_lining $3=$ & 0.005341 & $\mathrm{~m}$ \\
\hline & \multirow{4}{*}{$\sum_{n=0}^{Z}$} & \multirow{3}{*}{$\begin{array}{l}\text { 1-Compressibity ratio } \mathrm{C} \text {, no-slip lining } \\
\text { response coefficient(K2) \& Racking ratio }\end{array}$} & $\mathrm{C}=$ & 0.2203 & - \\
\hline & & & $\mathrm{K} 2=$ & 1.16596 & - \\
\hline & & & $\mathrm{R}=$ & 2.82 & - \\
\hline & & 2- Determined displacement, & $\Delta \mathrm{d}$ _lining $4=$ & 0.00539 & $\mathrm{~m}$ \\
\hline
\end{tabular}

Final $\Delta d$ lining is equal to $=\quad 0.0054 \quad \mathrm{~m}$

According to Tables 6 and 7, the maximum displacement is 5.4 $\mathrm{cm}$. Since Hashash et al relations calculate the effect of the surrounding land in the calculations for applying the first force surrounding land of the structure which is omitted in the program and then by fixing the structure floor, displacement is applied to the top. Figures (6 and 7).

Using the Section Builder program the final axial force- bending moment push is obtained for $45 \mathrm{~cm}$ section and considering the 2 reinforcement with $25 \mathrm{~mm}$ diameter and $20 \mathrm{~cm}$ distance (Fig. 8). Also the ratio of axial forces and bending moments created in the structure in two states of applying static and dynamic loads is obtained from the FLAC software and presented by points. The structure has the capacity to tolerate the attempts. Also within the arc, the structure needs to be strengthened which is why two rows of reinforcements are 
added. The results of analysis in this part indicate that although the level of axial forces in the final structure are increased compared to 50 $\mathrm{cm}$ lining, the structure has the ability to resist forces and moments and maintains its stability.

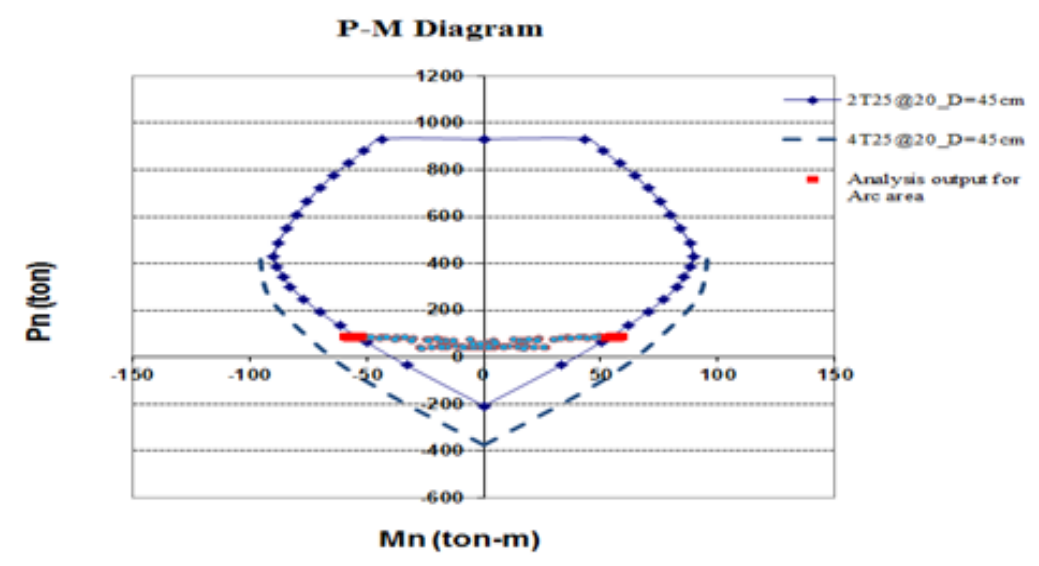

Figure 8. the capacity of axial force-bearing moment of the structure versus the results of analysis

\section{Cm lining thickness}

The reduction of lining thickness to $45 \mathrm{~cm}$ provides the necessary stability for the final structure. In the next stage, the analysis is performed for the lining of $40 \mathrm{~cm}$. After the final calculations, in the level of applying static loads of operation period the axial forces and moments in the maintenance system are considered with respect to the structural lining thickness of $40 \mathrm{~cm}$ (Fig 9 and 10). 


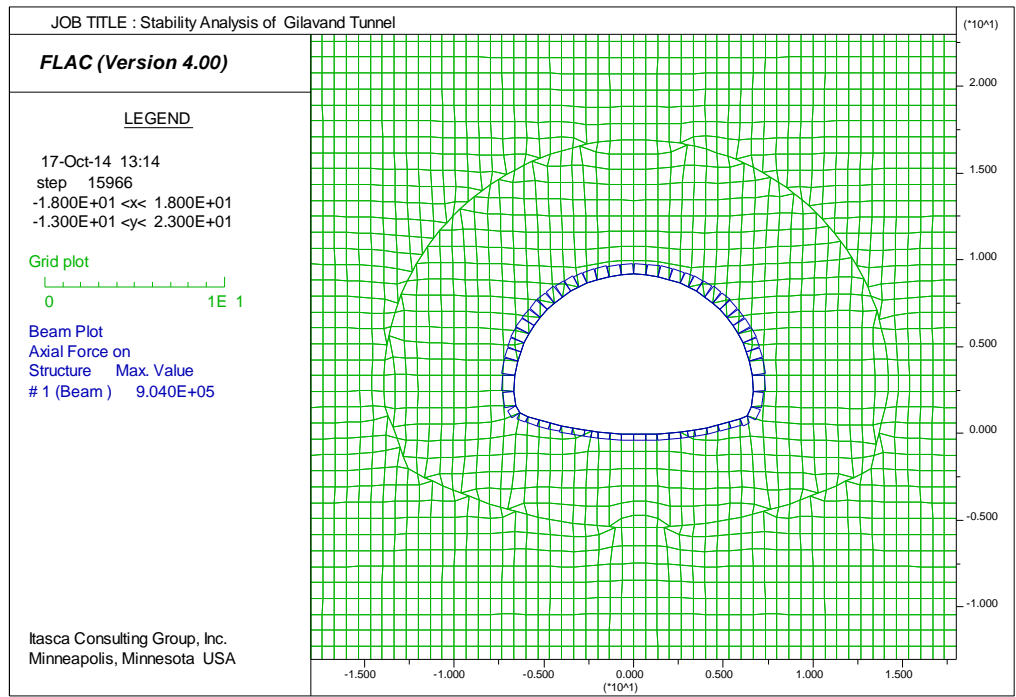

Figure9. The axial loads created in the structure after the final calculations

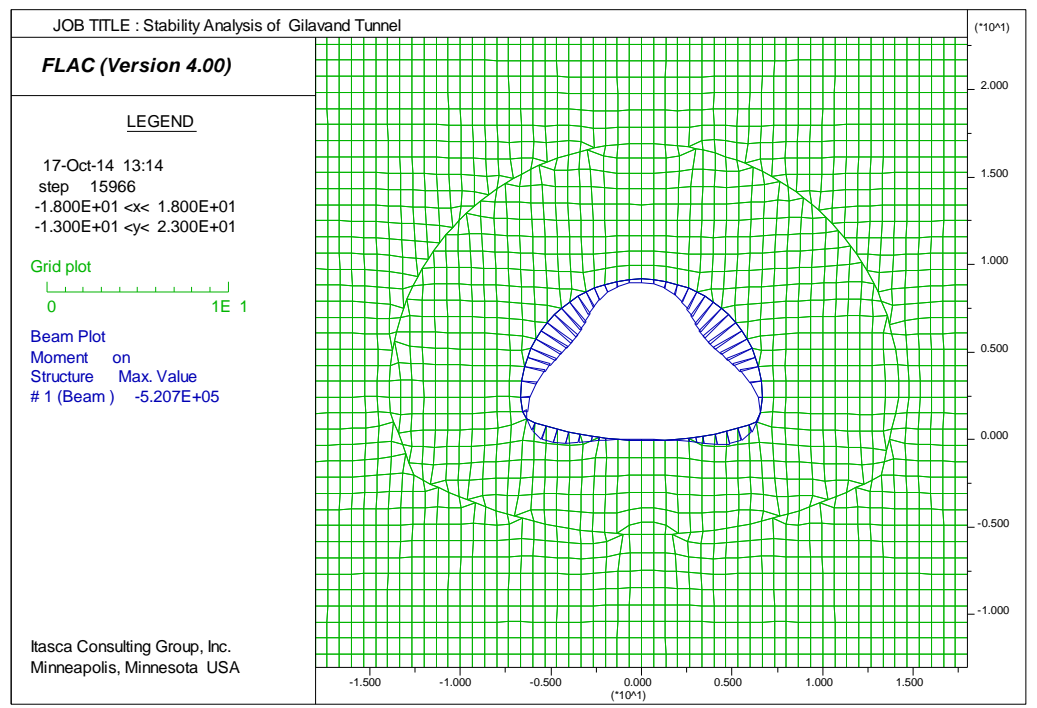

Figure10. The bending moments created in the structure after the final calculations 
Table 8.The input parameters for lining with the thickness of $40 \mathrm{~cm}$

\begin{tabular}{|c|c|c|c|}
\hline \multicolumn{4}{|c|}{ Input parameters - ODE } \\
\hline \multicolumn{4}{|c|}{ Geotechnical Parameters, } \\
\hline Unit Weight of the medium, & $\rho \mathrm{m}=$ & 1800 & $\mathrm{Kg} / \mathrm{m}^{\wedge} 3$ \\
\hline Poisson's ratio of the medium, & $v \mathrm{~m}=$ & 0.25 & - \\
\hline Modulus of elasticity of medium, & $\mathrm{Em}=$ & $3.00 \mathrm{E}+05$ & Kpa \\
\hline Shear Modulus of medium, & $\mathrm{Gm}=$ & 120000 & Kpa \\
\hline \multicolumn{4}{|c|}{ Tunnel Parameters, } \\
\hline Lining thickness, & $\mathrm{t}=$ & 0.4 & $\mathrm{~m}$ \\
\hline Lining diameter, & $d=$ & 10 & $\mathrm{~m}$ \\
\hline Lining radius, & $\mathrm{r}=$ & 5 & $\mathrm{~m}$ \\
\hline Depth below ground surface, & $\mathrm{h}=$ & 44 & $\mathrm{~m}$ \\
\hline Area of Tunnel Lining (per unit width), & $\mathrm{Al}=$ & 0.4 & $\mathrm{~m}^{\wedge} 2 / \mathrm{m}$ \\
\hline Moment of inertia of the tunnel lining, & Ic $=$ & 0.0053333 & $\mathrm{~m}^{\wedge} 4 / \mathrm{m}$ \\
\hline Poisson's ratio of the Concreate, & $v \mathrm{l}=$ & 0.2 & - \\
\hline Concrete yield strength, & $f^{\prime} c=$ & $2.40 \mathrm{E}+04$ & Kpa \\
\hline Concrete Young's Modulus, & $\mathrm{El}=$ & $2.32 \mathrm{E}+07$ & Kpa \\
\hline \multicolumn{4}{|c|}{ Earthquake Parameters, } \\
\hline Magnitude, & $\mathrm{Mw}=$ & 6.5 & - \\
\hline Source to site distance, & $\mathrm{ds}=$ & $0-20$ & $\mathrm{Km}$ \\
\hline Peak ground particle acceleration at surface, & $\operatorname{amax}=$ & 0.15 & $\mathrm{~g}$ \\
\hline Apparent velocity of S_wave propagation in medium, & $\mathrm{Cm}=$ & 258.2 & $\mathrm{~m} / \mathrm{s}$ \\
\hline \multicolumn{2}{|c|}{ Ratio of peak ground velocity $(\mathrm{cm} / \mathrm{s})$ to peak ground acceleration $(\mathrm{g})$, } & 94 & - \\
\hline \multicolumn{2}{|l|}{ Ratio of peak ground displacement $(\mathrm{cm})$ to peak ground acceleration $(\mathrm{g})$, } & 35 & - \\
\hline \multicolumn{2}{|l|}{ Ratios of ground motion at depth to motion at ground surface, } & 0.7 & - \\
\hline \multirow{3}{*}{ Ground motion at depth of tunnel, } & as $=$ & 0.105 & $\mathrm{~g}$ \\
\hline & $\mathrm{Vs}=$ & 0.0987 & $\mathrm{~m} / \mathrm{s}$ \\
\hline & $\gamma \max =$ & 0.0003823 & - \\
\hline
\end{tabular}

According to the above calculations, the maximum displacement is $5.5 \mathrm{~cm}$. As it can be seen, the reduced thickness up to $10 \mathrm{~cm}$ does not make a significance difference in the maximum induced displacement. In order to observe the corresponding coefficient of loading combination is multiplied by 1.3 and finally entered the program as the criterion of the displacement load $(7.04 \mathrm{~mm})$. The results of the forces and moments generated at the lining in section are represented in Figures 11 and 12. 
Table 9.The results of lining with the thickness of $40 \mathrm{~cm}$

\begin{tabular}{|c|c|c|c|c|c|}
\hline \multicolumn{6}{|c|}{ Calculation Results } \\
\hline \multirow{8}{*}{ 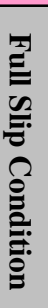 } & \multirow{4}{*}{ 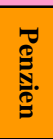 } & \multirow{3}{*}{$\begin{array}{l}\text { 1- Determine the racking ratio }(\mathrm{Rn}) \text { and the } \\
\text { displacement term } \Delta \text { d_free_field, }\end{array}$} & $\alpha n=$ & 0.045185 & - \\
\hline & & & $\mathrm{Rn}=$ & 2.87 & - \\
\hline & & & $\Delta \mathrm{d}$ _free_field $=$ & 0.0019 & $\mathrm{~m}$ \\
\hline & & 2- Determined displacement, & $\Delta \mathrm{dn} \_$lining $1=$ & 0.00549 & $\mathrm{~m}$ \\
\hline & \multirow{4}{*}{ 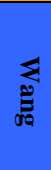 } & \multirow{3}{*}{$\begin{array}{l}\text { 1-flexibility ratio }(\mathrm{F}) \text {, full-slip lining } \\
\text { response coefficient }(\mathrm{K} 1) \text { \& Racking ratio, }\end{array}$} & $\mathrm{F}=$ & 38.7298 & - \\
\hline & & & $\mathrm{K} 1=$ & 0.11117 & - \\
\hline & & & $\mathrm{R}=$ & 2.87 & - \\
\hline & & 2- Determined displacement, & $\Delta \mathrm{d} \_$lining $2=$ & 0.00549 & $\mathrm{~m}$ \\
\hline
\end{tabular}

\begin{tabular}{|c|c|c|c|c|c|}
\hline \multirow{3}{*}{ 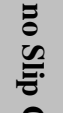 } & \multirow{3}{*}{ 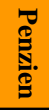 } & \multirow{2}{*}{ 1- Determine the racking ratio $(\mathrm{R})$, } & $\alpha=$ & 0.051640 & - \\
\hline & & & $\mathrm{R}=$ & 2.85 & - \\
\hline & & 2- Determined displacement, & $\Delta$ dn_lining $3=$ & 0.005452 & $\mathrm{~m}$ \\
\hline \multirow{4}{*}{ 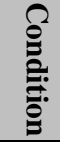 } & \multirow{4}{*}{$\sum_{00}$} & \multirow{3}{*}{$\begin{array}{l}\text { 1-Compressibity ratio C, no-slip lining } \\
\text { response coefficient }(\mathrm{K} 2) \text { \& Racking ratio }\end{array}$} & $\mathrm{C}=$ & 0.2479 & - \\
\hline & & & $\mathrm{K} 2=$ & 1.15533 & - \\
\hline & & & $\mathrm{R}=$ & 2.87 & - \\
\hline & & 2- Determined displacement, & $\Delta \mathrm{d} \_$lining $4=$ & 0.00549 & $\mathrm{~m}$ \\
\hline
\end{tabular}

Final $\Delta d \_$lining is equal to $=\quad 0.0055 \quad \mathrm{~m}$

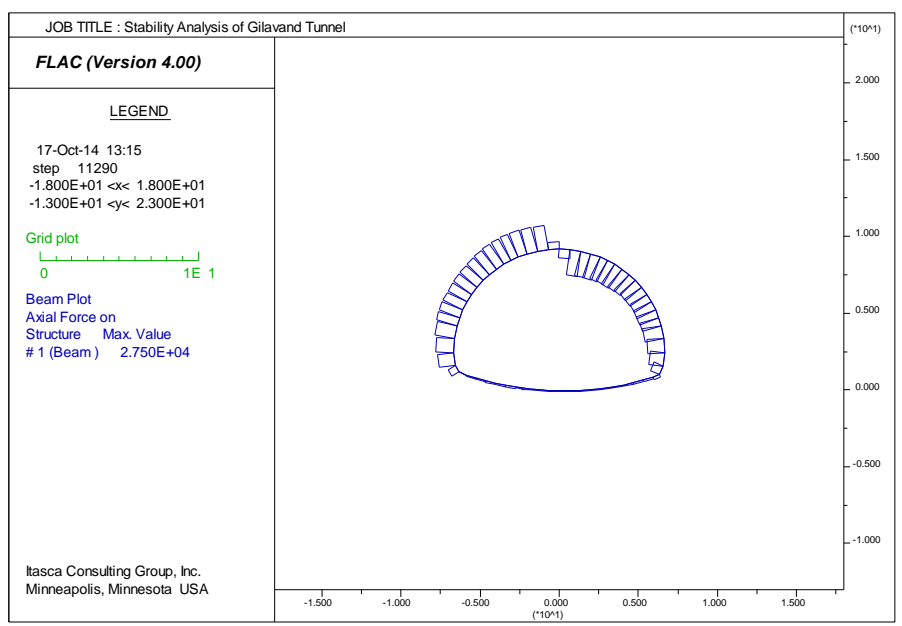

Figure11. The axial loads created in the structure after the final calculations 


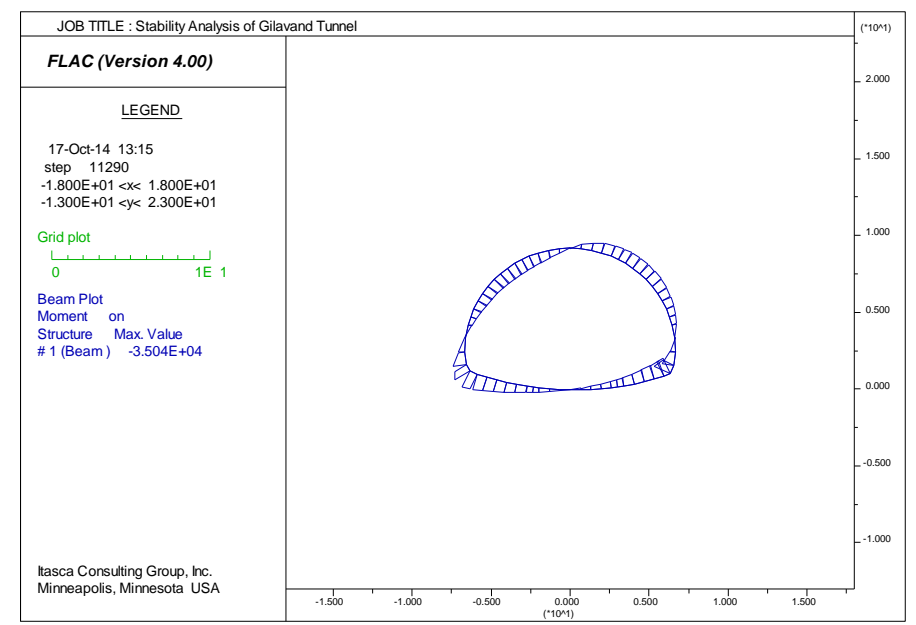

Figure 12. The bending moments created in the structure after the final calculations

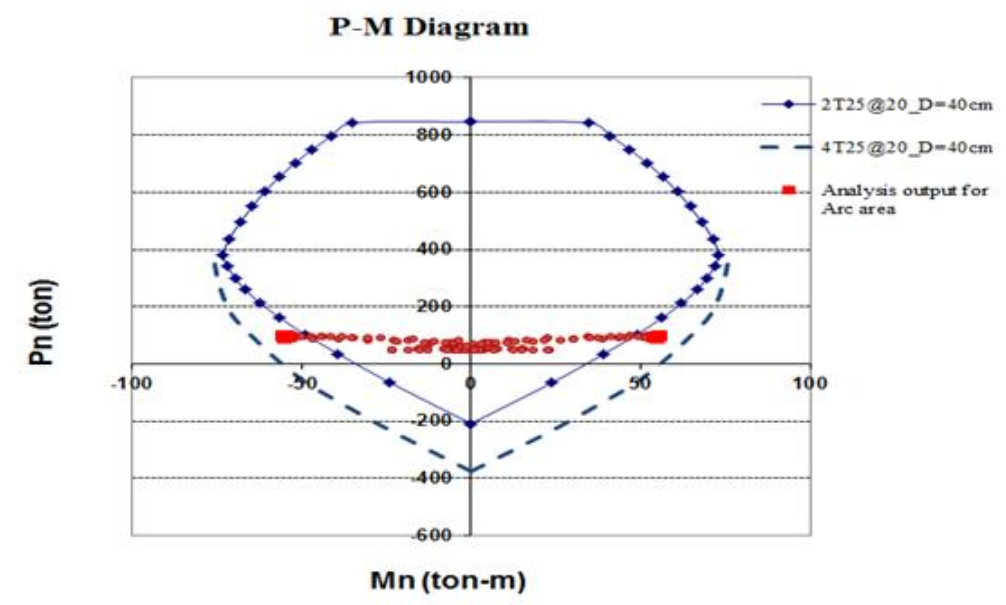

Figure 13, the capacity of axial force-bearing moment of the structure versus the results of analysis

Using the Section Builder program, the final axial force- bending moment push is obtained for $40 \mathrm{~cm}$ section and considering the 2 reinforcement with $25 \mathrm{~mm}$ diameter and $20 \mathrm{~cm}$ distance (Fig. 13). In addition, the ratio of axial forces and bending moments created in the 
structure in two states of applying static and dynamic loads is obtained from the Flac Software and presented by points. Even with considering the steel reinforcement in the arc like the previous models the created moments in the structure are above the tolerance level in some sections and it can be concluded that the structure does not have the necessary stability. The analysis of the induced moments in the structural elements indicate that the values above the tolerance level of the structure are extended from the lining wall up to the upper tips of the arc.

\section{Conclusion}

1. The design of the final structure of the tunnels (lining) is performed through the conventional hyper static method. In this method, the effect of soil reaction is simulated with the Winkler elastic springs through considering the linear behavior for the structure system and the effect of the static loads and the load of earthquake are measured during operation. Finally, the ratio of axial forces and moments created in the structure are controlled by the ultimate resistive limit. The design of the final maintenance systems is $50 \mathrm{~cm}$ of floor lining with 2 rows of $\varphi 25$ armature with $20 \mathrm{~cm}$ distance. In the lateral arcs, the lining is reinforced by two additional rows of $\varphi 25$ armatures while the analysis of the final maintenance system of Gilavand Tunnel is done by separate components and considering the land-shield interaction. The nonlinear behavior of the land indicated that the 
results with $50 \mathrm{~cm}$ thick lining structure and reinforcement is somehow similar to the results obtained from the hyper static method performed by the consultant engineer.

2. Based on the results of the numerical analyses, axial forces and moments created by the earthquake are much smaller than the forces and moments caused by static loads (dead load of the land and the weight of structure) so it can be said that in Gilavand tunnel, the static loads have the main role in designing the final structure. It seems that it is rational to consider that the nature of the land is surrounding the Gilavand Tunnel.

3. Analysis of maintenance system with lower thicknesses considering land-shield, indicated that applying the reinforced concrete with $40 \mathrm{~cm}$ thickness has the potential to tolerate the applied load but lining with $45 \mathrm{~cm}$ thickness is capable of tolerating the loads of design and it can be concluded that applying the simulation method combined with the soil and structure besides considering the nonlinear behavior of the soil leads to more economical results in a project.

\section{References}

1. Raul Fuentes, "Internal forces of underground structures from observed displacements", Tunneling and Underground Space Technology, Vol. 49, (2015). 
2. Ioannis Rigopoulos, Basilios Tsikouras, Panagiotis Pomonis, Konstantin Hatzipanagiotou, "Assessment of the engineering behavior of ultramafic and mafic rocks using chemical indices", Engineering Geology, Vol. 196 (2015) 222-237.

3. Hongyuan Zhou, Masuhiro Beppu, Guowei Ma, Zhiye Zhao," In-structure shock of underground structures: A revisit with experimental investigation", Engineering Structures, Vol. 56 (2013) 1620-1630.

4. Ilkka Vähäaho, "An introduction to the development for urban underground space in Helsinki".

5. Barton N., Lien R., Lunde J., "Engineering classification of rock masses for the design of tunnel support", Rock mechanics, 6 (4) (1974) 189-236.

6. Christian J.T., Desai C.S., "Numerical Methods in Geotechnical Engineering", McGraw-Hill (1977).

7. Itasca Co. Flac 3D- V.2.1. User Manual.

8. Federal Highway Administration (FHWA) "Technical Manual for Design and Construction of Road Tunnels", FHWA-NHI-09-01, USACI 318-08 (Mar. 2009).

9. Chapman D., Metje N., Stärk A., "Introduction to tunnel construction", (Vol. 3). CRC Press, (2010).

10. Section Builder Software- V.8, User Manual.

11. Bathe K.J., "ADINA-AFinite Element Program for Automatic Dynamic Incremental Nonlinear Analysis", Watertown (MA): ADINA Engineering Inc (1984).

12. "ATENA Program Documentation", (2012). 
13. Deutscher Ausschuss fur unterirdisches Bauene.V., "German Committee for Underground Construction", Recommendations for Executing and Application of unreinforced Tunnel Inner Linings. Tunnel, int. Journal of DAUB, D-50827 Koln, 5 (2007) 19-28.

14. AFTES Association Francaise des Tunnels et de 1 'EspaceSouterrain], "The use of plain concrete in tunnels" (2000).

15. Cao Y., Wang P., Jin X., Wang J., Yang Y., "Tunnel structure analysis using the multi-scale modeling method", Tunnelling and Underground Space Technology, 28 (2012) 124-134.

16. Aruga T., Arai Y., Tsuno K., "Non-linear stiffness behavior and analysis of tunnel lining with reinforcing bars", Quarterly Report of RTRI, 48 (1) (2007) 44-49.

17. Youakim S.A.S., El-Metewally S.E.E., Chen W.F., "Nonlinear analysis of tunnels in clayey/sandy soil with a concrete lining", Engineering structures, 22 (6) (2000) 707-722.

18. Wittke W., Pierau B., Erichsen C., "New austrian tunneling method (NATM)-stability analysis and design", WBI, Essen (2006).

19. Papanikolaou V.K., Kappos A.J., "Practical nonlinear analysis of unreinforced concrete tunnel linings", Tunnelling and Underground Space Technology, 40 (2014) 127-140.

20. Bieniawski Z.T., "Rock mechanics design in mining and tunneling", (No. Monograph) (1984). 
21. Hashash Y.M., Hook J.J., Schmidt B., John I., Yao C., "Seismic design and analysis of underground structures", Tunnelling and Underground Space Technology, 16 (4) (2001) 247-293.

22. Iran Esten Consulting Engineers, "Gilavand bypass tunnel engineering geology report" (2011).

23. Iran Esten Consulting Engineers, "Gilavand Tunnel report, the second stage of tunnel design" (2011) 